\title{
AN OVERVIEW FOR CUSTOMER RELATIONSHIP MANAGEMENT: EVALUATION FOR THE SERVICE INDUSTRY IN TERMS OF BUSINESS STRATEGY
}

\author{
DOI: 10.17261/Pressacademia.2020.1241 \\ PAP- V.11-2020(13)-p.62-66
}

\section{Aysenur Erdil}

Istanbul Medeniyet University, Istanbul, Turkey. runesyalidre@gmail.com, ORCID:0000-0002-6413-7482

To cite this document

Erdil, A., (2020). An overview for customer relationship management: evaluation for the service industry in terms of business strategy . PressAcademia Procedia (PAP), V.11, p.62-66

Permemant link to this document: http://doi.org/10.17261/Pressacademia.2020.1241

Copyright: Published by PressAcademia and limited licensed re-use rights only.

\begin{abstract}
Purpose- The purpose of this research is to define new cross-departmental processes for business which assign them to apply the four steps in the CRM cycle: plan, relation, process, leverage and then plan a new structure. From this point, this research includes the topic which has been preceded for a CRM solution. This study also involves a research management steps due to business application in service industry. In addition, the research comprises requirement analysis which depends on the business objectives-requirements for the service sector.

Methodology- During the research, the business and software development processes of the study were applied. After the business research development, architecture of requirements of software and UML (Unified Modeling Language) Structure of the service industry, big data were prepared and warehoused-stored for the next research and development for this area.

Findings- Finding methods and components of use cases and foundation of UML structures are fundamentals of the study during the research. This study classifies one of the hundreds of use cases as an instance and UML diagrams that define the work-flow of a specific point of business for the service industry.

Conclusion- Customers in Retail Industry were developed more price sensitive, less brand loyal and more sophis ticated. To provide guest loyalty, retailers in business tried to improve CRM strategies which purposes to seek, collect, store and separate guest information throughout the entire organization for creating personalized, unique visitors' experiences. Software solutions and new technologies could facilitate the new ways of working required by a CRM invention would not, in itself, deliver increased customer satisfaction.
\end{abstract}

Keywords: Business, Customer Relationship Management (CRM), Industry, Strategy, Service JEL Codes : L21, L80, L21

\section{INTRODUCTION}

Customer Relations Management (CRM) is a technique by which corporations maximize productivity through increasing customer loyalty. It is about automating and improving the customer-centric Sales, Marketing and Service business processes. It also chooses to focus on added customer loyalty that has a direct impact on the bottom line of the organization. CRM philosophy is an enterprise that gives a vision of how an enterprise wishes to deal with its clients. A CRM strategy that shapes sales, marketing, and customer service and analysis activities is required to achieve this vision. For most companies, the aim of a CRM approach is to optimize productive consum er interactions by growing the interest of both the vendor and the client. Frequently CRM applications only present one or two CRM process components. Consequently, a significant proportion of CRM programs focused on the introduction of a single product or series of software do not enhance consumer service, boost client engagement or provide the manufacturer with a return on investment in the form of improved revenue or benefit (Brown, 1999; Buttle, 2004; Lindstrand et al., 2006; Wang and Burton, 2008).

\section{LITERATURE REVIEW}

\subsection{Customer Relationship Management ( $\mathrm{Crm}$ ) - Oriented Market Strategy}

Therefore, any CRM initiative should start with a vision and strategy that defines the goals and goals of the company. You then need to adjust your organizational processes and structures so that you can effectively implement this strategy. Such procedures must be assisted by a CRM infrastructure that integrates contact channels with consumer data repositories and CRM applications. Moreover, if it is to support all four phases of the CRM life cycle, your investment in CRM must include instruments in all three domain solutions - 
collaborative, operational and analytical CRM (Gray and Byun; 2001; Greenberg, 2004; Bohling et al., 2006; Kumar, 2010). A CRM-based market strategy helps companies to recognize such high value clients and then treat them in a way that keeps them loyal. At the consumer's point of view, the importance of the partnership is a feature not only of the traditional "four Ps" price, product, position and promotion but also of the consistency of consumer experiences over time with a supplier. The number of effective customer networks, including the telephone, the World Wide Web, email, interactive digital television and traditional high street and direct mail, is becoming more and more complex as the customer demands are being met and the customer relationship is managed. Only if businesses embrace a strategic strategy that puts the client at the forefront of company strategies and procedures can they thrive. Furthermore, corporations need to visualize CRM as a cyclical process that treats customer relationships not as one-off events, but as interactions that develop and enhance over time in many years-term relationship (Firth, 2001; Winer, 2001; Kostojohn, 2011; Hillebrand et al., 2011). Business Performance and Requirements of Customers: Retail-service sector is distinguished by the assumption that consumer base awareness, preferences and behavioral features are important to growth. They are always working for customers and being with them during service, and must maintain high level of satisfaction so that they can collect feedback for future sales. Consumer spending was on the decline, and consumers became conscious of the value. Hotels, cafes, and restaurants are able to retain their core clients by increasing the standard of service. There are too many platforms that support that requirement. The research's starting point begins with the research into these solutions. Although certain conditions were looked for alternatives, certain of them are described in the Business specifications of the research.

\subsection{Process Of Business And Software Development}

Sustainable development comes with developer team appearances and there is no natural scientific method. The approach takes guidelines in which the efficient execution of the project comprises of a sequence of phases and processes with various methodologies. Common approach for application applications such as RUP (Rational Unified Process), CMM (Maturity Method of Capability). Generally at the end of the development process, the Agile Methodology follows a succession of steps with formal signs. The specifications of the user are collected, requirements are made, design is developed and the project is completed. Processes of Business and Software are managed in accordance with these segments, but procedures are carried out through various techniques, and the evaluation, development, design and deployment stages are classified into a dynamic couple of short adaptive development process which is an original strategy which is built by project teams for Cloud platform. The basic methodological characteristics are (Devlin and Murphy, 1988; Stevens and Pooley, 2000; Wilcoz and Gurău, 2003; Aier and Fischer, 2011). -The application developers are significantly smaller than usual. -The development staff is incorporated and deeply committed to the project ( i.e. consultants, project managers, testing staff). -The stages of development are shorter and very dynamic. -Every version release contains the actual customer needs functionality. -Releases are not whole prototypes but are work systems that are usable. -Tasks and activities are not carried out sequentially at the same time. The entire method is based on gradual improvements, typically culminating in a commodity of consistency. -The management manager knows that the work requires regular adjustments.

\section{MANAGEMENT OF BUSINESS AND SOFTWARE DEVELOPMENT}

The team members are a business goals analysis team, an analysis team for software demand, an architecture working group and a software development team. When data and report categories and tools were created, information such as documentation, data flow charts and entity - relationship diagram charts were evaluated which are used to transmit information. If the system architecture specifications are not appropriate, all methodologies will begin from the outset. If they are appropriate for proposed system, framework will continue with the software components being determined. The documentation and records are gathered by the program configuration review department, and functional and non-functional specifications were created. Modeling and software development operations begin after all those processes (Devlin and Murphy, 1988; Wilcoz and Gurău, 2003; Aier and Fischer, 2011). The issue is described something which has occurred that could threaten the outcomes of the program. With issue management, we can deal with barely conscious major problems, which indicate some problems that are not well recognized but that occur and could lead to problems in the next steps (March and Smith, 1995; Aier and Fischer, 2011; Blake and Mangiameli, 2013). For example, when the requirements gather together, some of them could indicate the same features but could not be implemented until the overall view comes so that some wrong logical aspects of the requirement analysis could be avoided. In comparison, there is another form of problem, mutual problems that remain class ified (March and Smith, 1995; Aier and Fischer, 2011; Blake and Mangiameli, 2013).

\subsection{Business Development and Change Management}

Change management is also the aspect that distinguishes performance and failure, this method is tailored to the project CRM. Although the industry of change management continues to expand through books, conferences and advisors, executives remain as frustrated as ever when challenged as part of the CRM program to incorporate effective change management. CRM attempts to customer-center the entire company and these new position directives structural changes throughout company. Successful change management consists of five key initiatives: internal marketing of transition, developing a appropriate change management framework, CRM-relevant planning, reconfiguring the corporate layout and success evaluation requirements, and remodeling current reward structures. Control of consumer partnerships has been described in different forms as infrastructure, a revolutionary method or a technique. While it has aspects of all of these, it is, above all, a customer-centric philosophy as old as the business strategy itself. In the ideal situation of CRM, this philosophy is transformed into a business model through the use of information systems and acceptable business systems. The outcome (again in the perfect world) is a smooth, reliable and excellent consumer service across a variety of touch points, which transforms into optimizing the company's partnership resources (Gray and Byun, 2001; Greenberg, 2004). The basic driving concepts for the implementation of transition often refer to CRM. Which include articulating a clear argument for reform, proactive commitment to people's concerns, beginn ing the project at the very top, engaging any tier in the company in the change effort, establishing high management control, designing an effective engagement plan, giving due consideration to the corporate climate and creating an effective program in incentives and 
punishments to communicate with channels In fact, if change strategy is to work, an enterprise 's existing consumers (the employees) will first be persuaded on the desire for improvement. Excluding effective staff buy-in, no CRM approach would definitely get out of the surface (Gray and Byun, 2001; Pan and Lee, 2003; Greenberg, 2004).

\subsection{Modeling-Unified Modeling Language (Uml)}

Models are already constructed so that we can better understand the process researchers are modeling, because we can not fully comprehend such a system. The simple implementation of reality that illustrates the system in its entirety from a biased viewpoint. Modeling is beneficial because it enables us to conceptualize, specify, construct and document the structure and behavior of the system architecture for the development team. Use a common modeling language such as the Unified Modeling Language (UML), members of the production team may easily express their conclusions to each other. UML is a structured entity simulation graphic programming tool. It is a terms of strategy based model with a graphical notation. This is used to build a conceptual system model, called a UML model. The UML can be used for computational systems architecture, statistical process control and organizational structure representation (Conallen, 2000; Wilcoz and Gurău, 2003; Glezer et al., 2005). The UML usually uses graphic notes to show software projects architecture. The UML assists the management team in collaborating, testing possible projects and validating the software's architectural Development (Conallen, 2000; Stevens and Pooley, 2000; Wilcoz and Gurău, 2003). Using UML Modeling provides improving strategies for automating software development and increasing efficiency and rising costs and time for business usage. This includes the technology of the components, visual programming, designs and frameworks. Companies are also looking for strategies to manage systems complexity as they grow in size and scale. They identify, in particular, the need to overcome recurring architectural problems, including physical distribution, competition, replication, safety, load balancing and defect tolerance. In fact it has compounded such technical issues with the introduction of the World Wide Web, thus simplifying other items (Stevens and Pooley, 2000; Conallen, 2000; Glezer et al., 2003)

\section{BUSINESS REQUIREMENTS}

\subsection{Overview (Background) of Business Requirements}

Business requirements evaluate the business goals that the client, corporation or project team wishes to achieve. The business objectives set a guidance framework for the remainder of the project. All other functionality and specifications of the company should comply with market requirements. Company specifications therefore do not have adequate information to tell developers what to build. Business specifications analysis team technical specifications after development of business processes. Typically requirements are expressed in the form of integration services, then they are described as Business Requirements Document (BRD). The purpose is to promote specifications of satisfactory value and detail to allow for the construction of realistic system development. Verification model for the company specifications contains these issues as below (March and Smith, 1995; Klincewicz, 2009; Liu et al, 2009; Blake and Mangiameli, 2013);

-Consumer or consumer needs: business prospects, customer goals and performance requirements, business threats;

-Vision of a solution: Statement of vision; Major features; -Range and limitations: original release width, eventual release range, restrictions. While it was investigated the evidence for the first portion of proposed systems, and then business opportunities were developed according to feasibility study. There are too many implementations that support that requirement. The research development launching point starts with the quest for certain answers. Four frameworks have been evaluated as to whether they may require this requirement with respect to the above requirements, varying from each other by which different business features they provide and the degree of sophistication and cost factors. For instance, while one can afford low-cost web sales, the other can focus on providing high-cost financials, payment systems (Devlin and Murphy, 1988; March and Smith, 1995; Klincewicz, 2009; Blake and Mangiameli, 2013).

\subsection{Perspective on Software Requirements}

Description on the Application Specifications includes three key parts: the framework overview, the general program definition and the particular specifications. The implementation provides us with information concerning the document itself. This material contains a description of the document's intent, a description of the nature of the program, a list of the meanings and acronyms include in the document, and a list of other documents cited in this text. The introduction also provides an description of the framework under which the specification under Program Requirements are relevant. After that developers should hold the generalization of the scope of the organization consistent with any existing documentation of the higher level regulations. This suggests that if the framework specifications definition, procedures principle, or dream framework occurs for the device, the two substances in this portion will be related together. Listing the high-level requirements is an acceptable way to provide this connection. Even we should carry-refer to higher-level specifications for the documentation relating to the categories of this software development (March and Smith, 1995; Stevens and Pooley, 2000. Aier and Fischer, 2011; Blake and Mangiameli, 2013). The purposed model for research management steps (improving CRM Strategy) due to business application in service industry for the Retail-service business. The entity and attributes relation diagram of using cases and foundation of UML structures are basis of the study during the study (see figure 1). 
Figure 1. Purposed Model for CRM Strategy for the Retail-Service Business

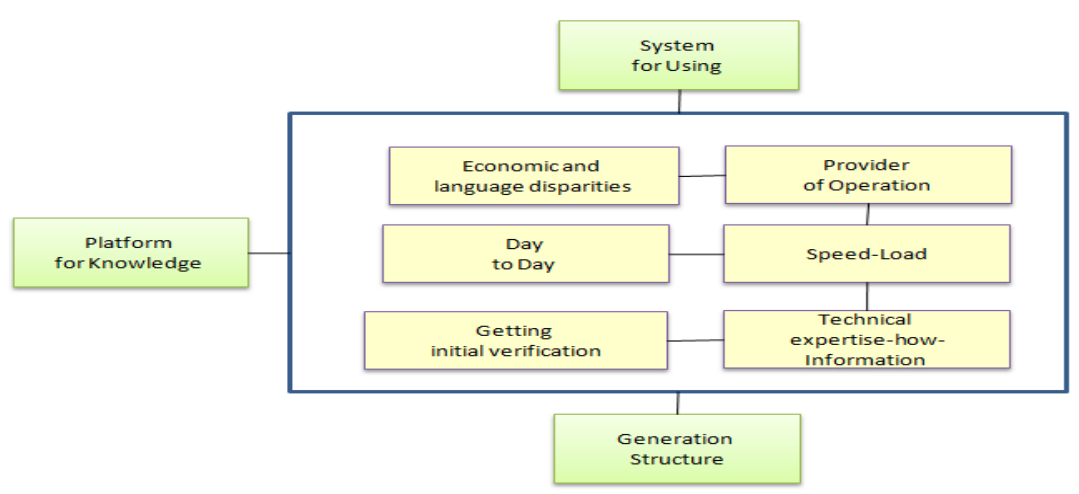

This model comprises three frameworks (I) System for Using, (ii) Platform for Knowledge, (iii) Generation Structure are integrated with same entities. These entities are Economic and Language disparities, Provider of Operation, Day to Day, Speed-Load, Getting Initial verification and Technical expertise-how-Information. If the system will interconnect with other systems as part of a larger system, the overview section of the introduction is the place to show that. Block diagrams are used for serving this purpose well. If the system stands alone, this is an acceptable place to include the system's context diagram. In some cases, we use both a block diagram and a context diagram. In either case, we should avoid duplicating information that exists elsewhere.

\section{CONCLUSION}

The description overall offers a full, conceptual representation of the situation. Business, user, and system requirements are specified elsewhere where they exist. The report on the Program Specifications includes a segment on product viewpoint such that this framework can be presented in detail. To this end, there are five parts of the ultimate description: Product Viewpoint, Product Features, and Consumer Characteristics. Assumptions and Dependencies, and Requirement Allocation. For the Change Management System, the phase of the Software Requirements has been included. The purposed model of the study (CRM Model-Information Security) is to investigate the relation between the frameworks and the properties of the framework of information management structure for the design Inform ation System (IS) and the IS with UML. The proposed CRM structure and factors of the suggested model support and enhance the management information processes and help business, users, and customers to survive and compete within today's complex and dynamic envir onment. In today's world, Internet is the leading technology that affects our lives and the way we look at the future. The aim of this research was to get the knowledge and learn the technology behind Internet, and also to learn more about customer relation using Internet. CRM is nowadays a popular application in business life to maintain the activities in the best way by having better relations with the customers and shaping the processes of CRM according to their present and possible needs.

\section{REFERENCES}

Aier, S., and Fischer, C. (2011). Criteria of progress for information systems design theories. Information Systems E-Business Management, 9, 133-172.

Blake, R., and Mangiameli, P. (2013). An Information systems design theory for strategic decision systems: the case of a candy manufacturer, Northeast Decision Sciences Institute Annual Meeting Proceedings.

Bohling, T. , Bowman, D., LaValle, S., Mittal, V. and Narayandas, G.D.(2006) CRM Implementation: Effectiveness Issues and Ins ights, Journal of Service Research, 9(2), 184-194. https://doi.org/10.1177/1094670506293573

Brown, S. A. (1999). Customer relationship management: A strategic imperative in the world of e-business. Etobicoke: Wiley.

Buttle, F. (2004) Customer Relationship Management: Concept and tools. Burlington, MA: Elsevier.

Conallen, J. (2000). Building Web Applications with UML. Addison Wesley Longman, London

Devlin, B. A. and Murphy, P. T.(1988). An architecture for a business and information system, IBM Systems Journal, 27(1), 60-80.

Firth, D. (2001). The organizing vision for customer relationship management. In AMCIS 2001 Proceedings, 162, 834-840, Boston, MA. Retrieved from http://aisel.aisnet. org/amcis2001/162.

Glezer, C., Nachmany, E. and Shoval, P. (2005). Quality and comprehension of UML interaction diagrams-an experimental comparison, Information and Software Technology, 47, 675-692. https://doi.org/10.1016/j.infsof.2005.01.003

Gray, P. and Byun, J. (2001), Customer Relationship Management, Center for Research on Information Technology and Organizations University of California, March 2001.

Greenberg, P. (2004). CRM at the Speed of Light: Capturing and Keeping Customers in Internet Real Time, McGraw-Hill, Berkeley, CA. 
Hillebrand, B., Nijholt, J., and Nijssen, E. (2011). Exploring CRM effectiveness: An institutional theory perspective. Journal of the Academy of Marketing Science, 39, 592-608.

Klincewicz, K. (2009). Knowledge management and IT research and analysis firms: Agenda-setters, oracles and judges, In D. Jemielniak \& J. Kociatkiewicz (Eds.), Handbook of research on knowledge-intensive organizations, 152-168, Hershey, PA, IGI Global.

Kostojohn, S., Johnson, M. and Paulen, B. (2011), CRM Fundamentals, Apress Publishing, 244 p.

Kumar, V. (2010). Customer relationship management. Hoboken, NJ: Section in Wiley International Encyclopedia of Marketing.

Lindstrand, A., Johanson,J. and Sharma, D.D. (2006) Managıng Customer Relationships On The Internet, Series Pervez N. Gha uri (Ed.), First Edition, Elsevier Inc. ISBN-13: 978-0-08-044124-5, $319 \mathrm{p}$

Liu, S., Duffy A. H. B., Whitfield, R. I., and Boyle, I. M. (2009). Integration of decision support systems to improve decision support performance, Knowledge and Information Systems, 22(3), 261-286.

March, S. T., and Smith, G. F. (1995). Design and natural science research on information technology. Decision Support Systems, 15(4), 251266

Pan, S. L., and Lee, J.N. (2003). Using e-CRM for a unified view of the customer. Communications of the ACM, 46, 95-99.

Stevens, P. and Pooley, R. (2000). Using UML Software Engineering with Object and Components. Updated Edition. Pearson Education Limited, Harlow.

Wang, P. and Burton Swanson, E. (2008). Customer relationship management as advertised: Exploiting and sustaining technological momentum. Information Technology and People, 21, 323-349.

Wilcoz, P.A. and Gurău, C. (2003). Business modelling with UML: the implementation of CRM systems for online retailing, 3, 181-191, https://doi.org/10.1016/S0969-6989(03)00004-3.

Winer, R. S. (2001). A framework for customer relationship management. California Management Review, 43, 89-105. 